\title{
DIAGNOSIS AND MANAGEMENT OF ANTERIOR CSF LEAKS: OUR EXPERIENCE
}

Probal Chatterji1 ${ }^{1}$, Rahul Ranjan ${ }^{2}$

\section{HOW TO CITE THIS ARTICLE:}

Probal Chatterji, Rahul Ranjan. "Diagnosis and Management of Anterior CSF Leaks: Our Experience". Journal of Evolution of Medical and Dental Sciences 2015; Vol. 4, Issue 40, May 18; Page: 6981-6988,

DOI: $10.14260 /$ jemds/2015/1014

ABSTRACT: CSF leaks through the nose (CSF rhinorrhea) may occur due to defects in the anterior, middle or posterior cranial fossa. Among them, anterior CSF leaks are most commonly encountered in clinical practice and may be traumatic or spontaneous in origin. A prompt diagnosis is essential as the main risk of a persistent leak is the chance of developing life threatening meningitis. Radiological imaging by non-contrast high-resolution CT scan is the initial investigation of choice and shows the site of leak in most cases. In case of recent onset leaks, a period of conservative management is indicated. If conservative management fails, then the traditional neurosurgical procedures like craniotomy and other open approaches were the most preferred line of management of such leaks till a few years back. But now endoscopic repair of these leaks has provided a better alternative because of reduced surgical morbidity, hospital stay and costs. We present our initial experience with seven cases of anterior CSF rhinorrhea which were encountered in a two year period in our institute. Two out of three cases with recent onset leaks healed spontaneously with medical management while five cases required endoscopic repair with two surgical failures.

KEYWORDS: CSF Rhinorrhea, Diagnosis of CSF Leaks, Endoscopic repair of CSF Leaks.

INTRODUCTION: CSF rhinorrhea signifies a communication of the subarachnoid space with the exterior due to an opening in the dura mater and arachnoid mater coupled with an osseous defect. This defect may be congenital or acquired and may be located in the anterior, middle or posterior cranial fossabut will manifest as CSF rhinorrhea. ${ }^{1}$ Along with this a CSF pressure gradient that is continuously or intermittently raised may also play an important role in some cases.

About $80 \%$ of CSF leaks are secondary to head trauma with an associated skull base fracture while only $3-4 \%$ cases are non-traumatic or spontaneous in origin. ${ }^{2}$ In traumatic cases, mostly the anterior cranial fossa is involved. ${ }^{3}$ The most common location of the defect is the region of the fovea ethmoidalis and posterior wall of frontal sinus followed by the cribriform plate of ethmoid and the sphenoid sinus. ${ }^{4}$ Non-traumatic CSF leaks as already mentioned are rare and may be high pressure (45\%) or normal pressure leaks (55\%). 5

The main risk of a persistent CSF leak is the potential to develop life threatening infective meningitis. ${ }^{6}$ The factors that seem to operate in the development of meningitis include the duration of the leak, its site and the presence of local contamination due to open wounds in the head-neck region (as in severe road traffic accidents) and active sinus infections.

A non-contrast high-resolution CT scan of the brain and maxillofacial region is usually the investigation of choice for demonstration of the site of leak.7 


\section{ORIGINAL ARTICLE}

With a recent onset post-traumatic CSF leak, conservative management is always attempted first with the hope of avoiding surgery. It includes the following measures:

- Absolute bed rest with the head end of the bed raised by at least $30^{\circ}$.

- Anti-tussives and anti-histaminics are given to control coughing and sneezing if indicated.

- Anti-emetics are given to control vomiting \& retching which is common in patients with head injury.

- Stool is kept soft by using agents like Isabgol husk to avoid straining.

- Blood pressure is strictly controlled by giving anti-hypertensive agents if indicated.

- CSF diversion with a lumber drain (or less commonly by repeated lumber punctures) to reduce the CSF pressure is also done in certain Center's in conjunction with the above measures to improve the success rate of conservative management.

Role of prophylactic antibiotics for preventing meningitis is controversial. While some previous studies showed a reduced incidence of meningitis on giving prophylactic antibiotics, recent literature does not support the view. ${ }^{8}$ Rather, unwarranted use of prophylactic antibiotics may cause development of drug-resistant strains of bacteria. Present recommendation is to use antibiotics only during the Peri-operative period for patients undergoing surgery for closure of the leaks and certain special circumstances like gross local contamination in accident victims etc.

The duration up to which conservative treatment should be tried for recent onset leaks is a matter of great debate. Resolution rates may be as high as $85 \%$ (for all types of CSF leaks combined) if conservative management is extended up to a week after onset of leak compared to 3-4 days only. ${ }^{9}$

Secondly and more importantly, it has been noted that if the period of conservative management exceeds one week, there is a eight to ten fold increase in the risk of meningitis over the first week.10,11 Therefore, present recommendation is for a trial of conservative management for not more than 7 days.

For reasons mentioned above, a recent onset anterior CSF leak which fails to resolve with conservative management and old leaks are an absolute indication for surgical repair.

The various surgical approaches employed over the last century by neurosurgeons and otolaryngologists can be broadly categorized as intra-cranial (Craniotomy approach) or extra-cranial (Frontal osteoplastic flap/ external ethmoidectomy approach etc). The particular technique adopted depends on the site and size of the leak. But all these approaches have certain limitations as mentioned below:

- Surgical morbidity-This is the main disadvantage of the open operations as these are major procedures with prolonged recovery time.

- Intra-cranial procedures involve brain handling and retraction with frequent complaints like loss of smell and seizures in some cases etc.

- Time of operation and subsequent duration of stay in the hospital (Including ICU stay) is often prolonged leading to high costs especially in patients with co-existent medical complications.

All of these can be avoided or minimized by trans-nasal endoscopic repair of CSF leaks. Ironically, the advent of Functional Endoscopic Sinus Surgery (FESS) about 3 decades ago commonly resulted in iatrogenic CSF leaks but also provided the far less morbid approach for repair of the same which may develop due to FESS itself or any other etiology. ${ }^{12}$ 


\section{ORIGINAL ARTICLE}

Mattox and Kennedy, ${ }^{13}$ have stated some additional advantages of endoscopic repair of anterior CSF leaks over the traditional approaches. They are summarized as follows:

- Excellent field of vision and exact localization of the defect is possible by using a nasal endoscope.

- Magnified view of the operative field on the monitor helps to precisely clean the mucosa from the edges of the bony defect to allow sealing of the latter with accurate positioning of the graft.

We have thus undertaken a study of the diagnosis and management of anterior CSF leaks primarily from an otorhinolarygological perspective in our institute. All the cases that were encountered in a two year period have been included in this study. Our experience is discussed in detail below.

MATERIALS AND METHODS: The department of ENT along with the department of Radiodiagnosis at Rama Medical College-Hospital, Kanpur has undertaken a study of the diagnosis and treatment outcome of patients with anterior CSF leaks. The study was done over a 2 year period from April 2013 to March 2015 in which seven patients were diagnosed with the condition. Patients were chosen from those attending the Emergency as well as those attending the OPD.

Initially all patients with a suspected CSF leak were advised non contrast high-resolution CT scan of the brain and maxillofacial region. CT was done in the axial and coronal planes using $1 \mathrm{~mm}$ thick contiguous sections and images were also reformatted in sagittal section. The field of view was 150 to $180 \mathrm{~mm}$ using a $512 \times 512$ matrix. A bone algorithm was used to enhance bone detail in all studies. A positive outcome consisted of the demonstration of a bony defect with adjacent extracranial fluid collection and/or mucosal thickening.

A trial of conservative management was instituted in recent onset leaks and the rest (i.e., old cases and those which did not respond to conservative management) were managed by surgical repair of the leak by endoscopic approach.

We have followed the standard protocol for conservative management (as discussed above) for a period of seven days in all the three cases presenting immediately after the onset of the leak. Two cases had spontaneous closure of the leak while another did not respond and had to be operated. The other four were old cases and thus they were prepared for endoscopic repair without delay.

The repair itself was done under GA in all cases using fat reinforced by fascia lata and fibrin glue. A Merocel nasal pack was given after completion of the OT. In the post-operative period the patient was kept in the ward in absolute bed-rest with the head-end raised for 4 days. An intravenous antibiotic was started from the night before surgery and given for 7 days post-operatively along with Acetazolamide. The Merocel pack was removed on the $4^{\text {th }}$ post-operative day. Patient was allowed ambulation from the $5^{\text {th }}$ day and discharged from hospital on the $7^{\text {th }}$ day with advice to avoid any physical exertion for six weeks.

RESULTS: The details of the patient profile, history of head injury or previous surgery, the duration and site of leak, mode of management (i.e., conservative or surgical) and treatment outcome are summarized in a Table below. 


\section{ORIGINAL ARTICLE}

\begin{tabular}{|c|c|c|c|c|c|c|c|}
\hline $\begin{array}{c}\text { Patient } \\
\text { profile } \\
\text { (age/sex) }\end{array}$ & Etiology & $\begin{array}{c}\text { Duration } \\
\text { of leak }\end{array}$ & $\begin{array}{c}\text { Site of leak } \\
\text { as detected } \\
\text { by CT scan } \\
\text { findings }\end{array}$ & $\begin{array}{c}\mathrm{H} / \mathrm{o} \\
\text { meningitis }\end{array}$ & $\begin{array}{c}\text { Outcome of } \\
\text { conservative } \\
\text { management }\end{array}$ & $\begin{array}{c}\text { Whether } \\
\text { surgery } \\
\text { done }\end{array}$ & $\begin{array}{l}\text { Final } \\
\text { result }\end{array}$ \\
\hline $10 /$ male & $\begin{array}{l}\text { Head } \\
\text { injury }\end{array}$ & 3 days & $\begin{array}{c}\text { \# fovea } \\
\text { ethmoidalis } \\
\text { \& posterior } \\
\text { wall of } \\
\text { frontal sinus } \\
\text { on left }\end{array}$ & $\begin{array}{c}\text { Yes } \\
\text { (controlled } \\
\text { with iv } \\
\text { antibiotics } \\
\text { after } \\
\text { admission) }\end{array}$ & Successful & No & $\begin{array}{c}\text { Succes } \\
\text { sful }\end{array}$ \\
\hline $39 / \mathrm{m}$ & $\begin{array}{l}\text { Head } \\
\text { injury }\end{array}$ & 5 days & $\begin{array}{l}\text { \# posterior } \\
\text { wall of } \\
\text { frontal sinus } \\
\text { on right }\end{array}$ & No & Successful & No & $\begin{array}{c}\text { Succes } \\
\text { sful }\end{array}$ \\
\hline $29 / \mathrm{f}$ & $\begin{array}{l}\text { Head } \\
\text { injury }\end{array}$ & 3 days & $\begin{array}{l}\text { \# cribriform } \\
\text { plate on left }\end{array}$ & No & Failed & Yes & $\begin{array}{c}\text { Succes } \\
\text { sful }\end{array}$ \\
\hline $26 / \mathrm{m}$ & $\begin{array}{l}\text { Head } \\
\text { injury }\end{array}$ & $\begin{array}{c}6 \\
\text { months }\end{array}$ & $\begin{array}{c}\text { \# fovea } \\
\text { ethmoidalis } \\
\text { on right }\end{array}$ & No & Not applicable & Yes & $\begin{array}{c}\text { Succes } \\
\text { sful }\end{array}$ \\
\hline $41 / \mathrm{m}$ & $\begin{array}{l}\text { Head } \\
\text { injury }\end{array}$ & 1 year & $\begin{array}{c}\text { \# fovea } \\
\text { ethmoidalis } \\
\text { and } \\
\text { cribriform } \\
\text { plate on } \\
\text { right }\end{array}$ & $\begin{array}{c}\text { Yes } \\
\text { (4 months } \\
\text { ago) }\end{array}$ & Not applicable & Yes & $\begin{array}{c}\text { Succes } \\
\text { sful }\end{array}$ \\
\hline $50 / \mathrm{f}$ & $\begin{array}{c}\text { No } \\
\text { apparent } \\
\text { cause }\end{array}$ & $\begin{array}{c}15 \\
\text { months }\end{array}$ & $\begin{array}{l}\text { Collection in } \\
\text { left } \\
\text { ethmoids } \\
\text { but no } \\
\text { definite site } \\
\text { of leak }\end{array}$ & No & Not applicable & Yes & $\begin{array}{c}\text { Failed } \\
\text { to cure } \\
\text { leak }\end{array}$ \\
\hline $34 / \mathrm{m}$ & $\begin{array}{l}\text { Previous } \\
\text { h/o fess } \\
\text { for } \\
\text { ethmoidal } \\
\text { polyps }\end{array}$ & $\begin{array}{c}8 \\
\text { months }\end{array}$ & $\begin{array}{c}\text { Bony } \\
\text { dehiscence } \\
\text { of fovea } \\
\text { ethmoidalis } \\
\text { on left }\end{array}$ & No & Not applicable & Yes & $\begin{array}{c}\text { Failed } \\
\text { to cure } \\
\text { leak }\end{array}$ \\
\hline
\end{tabular}

DISCUSSION: In our study we find that three cases had a recent onset leak with positive history of head injury in all the cases (100\%). Among the four old cases, two had positive history of head injury while one was a case of iatrogenic CSF leak due to previous endoscopic nasal surgery. No suggestive cause could be found in one case.

Non contrast high-resolution CT scan findings of the patients showed an obvious site of leak in six out of the seven cases (85.7\%) while no bony defect could be visualized in one $(14.3 \%)$. There was however a definite collection within the ethmoidal sinus on one side in the latter and the biochemical examination of the nasal fluid was suggestive of CSF. 


\section{ORIGINAL ARTICLE}

Interestingly, the latter was the case where a definite history of head injury or previous surgery was also absent. There is a definite controversy regarding the best investigation for patients with a suspected CSF leak, but the study by Stone et $\mathrm{al}^{7}$ mentioned above also found non contrast high-resolution CT scan to be the initial investigation of choice to screen patients with a success rate of $71 \%$ in their case series of 42 patients. In fact, they concluded that other complex procedures like CT cisternography and radionuclide cisternography (Which is available in selected centers) do not offer any extra advantage over non contrast high-resolution CT scan for detecting the site of leak. In their study there was no patient with positive result at CT cisternography and radionuclide cisternography who did not initially have bony defect revealed by non-contrast high-resolution CT scan. Rather, there were 10 patients in their series with defects revealed by non-contrast highresolution CT scan in whom no leak was apparent by either CT cisternography or radionuclide cisternography.

Among our six cases with a history of head injury or previous surgery, four cases had a single site of bony dehiscence while two had multiple sites of dehiscence. Overall, the fovea ethmoidalis was the most commonly involved in four cases (57.1\%) followed by the cribriform plate of ethmoids and posterior wall of frontal sinus involvement in two cases each (28.6\%). Fig. 1 and 2 shows the site of leak in two of the cases.

Two out of the three cases with a recent onset leak recovered with conservative management $(66.67 \%)$. The one which failed to heal with conservative means and the other four cases were operated with three successes (60\%) and two failures (40\%). During surgery we found a definite correlation between the CT scan findings and intra-operative findings in all cases with a known defect. This is in total agreement with the findings of Stone et al.7 Another study by Lloyd et al, ${ }^{14}$ also found good correlation between pre-operative CT scan findings and operative findings in a series of 13 patients.

A review of the available literature shows a success rate of $92 \%$ for first attempt closures in a large series of 289 patients who had undergone endoscopic repair of CSF leaks. ${ }^{15}$ A recent 10- year study published in 2013 also corroborates this view. ${ }^{16}$ It is therefore safe to opine that anterior CSF leaks that do not respond to conservative management are probably best managed by endoscopic repair in the first attempt as they score over conventional approaches, the relative advantages and disadvantages of which have already been mentioned above.

The main reasons attributable to failure of endoscopic repairs are elevated intra-cranial pressure, morbid obesity with elevated body-mass index (BMI) and lateral sphenoidal leaks. ${ }^{17}$

Another factor that strongly predisposes to recurrence of a leak is where patching is done over the suspected area in absence of pre-therapeutic topographical diagnosis. Finally it cannot be over emphasized that the experience of the surgeon and adequate skill of using the endoscope is also a must for good results.

We would refrain from comparing our results to the above mentioned studies as our study has been done in a Medical College located in a semi-urban location of India and the present series is consisting of seven cases only, while most of the large case series that have been referred to have been performed by extremely experienced surgeons in tertiary centers in the developed world.

In conclusion, it must however be acknowledged that in spite of the good results of endoscopic repair, the neurosurgical procedures and external approaches cannot be written off yet. 


\section{ORIGINAL ARTICLE}

They also have their role in the management of anterior CSF leaks in certain situations. At present their indications are as follows:

- The presence of skull-base defects at a location not readily visualized by the endoscope.

- Revision cases where endoscopic repair has failed.

- Cases with multiple areas of dehiscence.

CONCLUSION: Non contrast high-resolution CT scan is the initial investigation of choice to screen patients with a suspected CSF leak. Conservative management for up to a week should definitely be attempted initially in cases with recent onset CSF leaks. For those patients requiring surgical intervention, endoscopic repair of anterior CSF leaks have a number of advantages over traditional intra and extra-cranial procedures in terms of surgical morbidity, duration of hospital stay and cost of treatment etc., along with better visualization of the operative field. There is a definite correlation between the CT scan findings and intra-operative findings in cases with a known defect and success rate is over $90 \%$ for first attempt closures in most large case series. Thus they should be employed as a first-line approach. However, some primary cases where the defect cannot be visualized endoscopically or where endoscopic repair has failed definitely warrant the traditional open procedures.

\section{REFERENCES:}

1. Milford C A. Scott-Brown's Otolaryngology $6^{\text {th }}$ ed. Butterworth-Heinmann. 1997; 4: 14/1-10.

2. Beckhardt R N, Setzen M, Carras R. Primary spontaneous cerebrospinal fluid rhinorrhea. Otolryngology - Head and Neck Surgery. 1991; 104: 425-432.

3. Calcaterra C T. Extracranial surgical repair of cerebrospinal fluid rhinorrhea. Annals of Otology, Rhinology and Laryngology. 1980; 89: 108-116.

4. Park J, Strelzow V V, Friedman W H. Current management of cerebrospinal fluid rhinorrhea. Laryngoscope. 1983; 93: 1294-1300.

5. Shugar J M A, Som P M, Eisman W, Biller H F. Non-traumatic cerebrospinal fluid rhinorrhea. Laryngoscope. 1981; 91: 114-119.

6. Chandler J R. Traumatic cerebrospinal fluid leakage. Otolaryngologic Clinics of North America. 1983; 16: 623-32.

7. Stone J A, Castillo M, Neelon B, Mukherji S K. Evaluation of CSF Leaks: High-resolution CT compared with contrast-enhanced CT and radionuclide cisternography. Am J Neuroradiol. 1999; 20: 706-712.

8. Prosser J D, Vender J R, Solares C A. Traumatic Cerebrospinal Fluid Leaks. Otolaryngol Clin N Am. 2011; 44: 857-73.

9. Bell R B, Dierks E J, Homer L et al. Management of cerebrospinal fluid leak associated with craniomaxillofacial trauma. J Oral Maxillofac Surg. 2004; 62 (6): 676-84.

10. Leech P J, Paterson A. Conservative and operative management for cerebrospinal fluid leakage after closed head injury. Lancet. 1973; 1 (7811): 1013-6.

11. Mincy J E. Posttraumatic cerebrospinal fluid fistula of the frontal fossa. J Trauma. 1966; 6: 61822.

12. Wigand M E. Transnasal ethmoidectomy under endoscopic control. Rhinology. 1981; 19: 7-15.

13. Mattox D E, Kennedy D W. Endoscopic management of cerebrospinal fluid leaks and cephaloceles. Laryngoscope. 1990; 100: 857-862. 


\section{ORIGINAL ARTICLE}

14. Lloyd M N H, Kimber P M, Burrows E H. Post-traumatic cerebrospinal fluid rhinnorhoea: Modern high-definition computed tomography is all that is required for the effective demonstration of the site of leakage. Clin Radiol. 1994; 49: 100-103.

15. Hegazy G M, Carrau R L, Cynderman C H. Transnasal endoscopic repair of cerebrospinal fluid rhinorrhea - a meta-analysis. Laryngoscope. 2000; 110: 1166-1172.

16. Schoentgen C, Henaux P L, Godey B, Jeqoux F. Management of post-traumatic cerebrospinal fluid leak of anterior skull base - 10 years' experience. Acta Otolaryngol. 2013 Sept; 133 (9): 944-50.

17. Basu D, Haughey B H, Hartman J M. Endoscopic cerebrospinal fluid leak repair. Otolryngology Head and Neck Surgery. 2006; 135: 769-773.

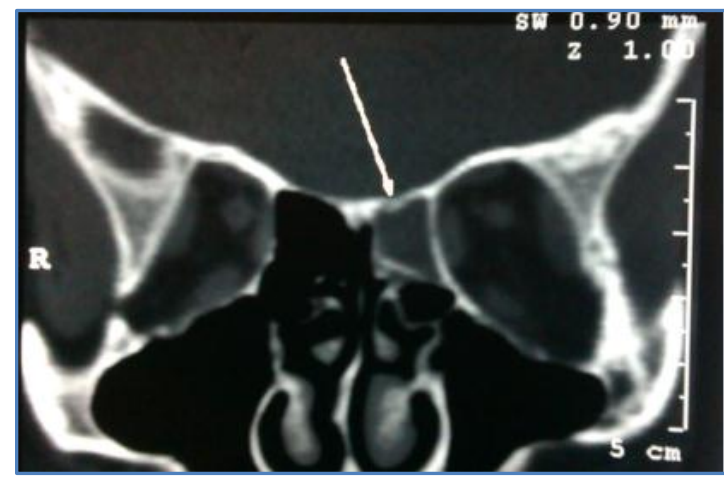

Fig. 1: Fracture of the ethmoidal roof on left

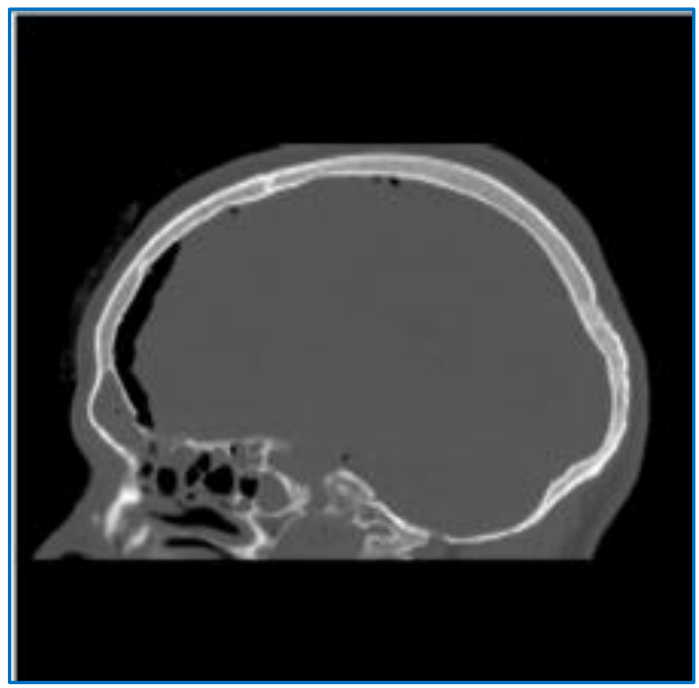

Fig. 2: Fracture of posterior table of right frontal sinus with pneumocephalus 


\section{ORIGINAL ARTICLE}

\section{AUTHORS: \\ 1. Probal Chatterji \\ 2. Rahul Ranjan}

\section{PARTICULARS OF CONTRIBUTORS:}

1. Associate Professor, Department of ENT, Rama Medical College Hospital \& Research Centre, Kanpur.

2. Assistant Professor, Department of Radiodiagnosis, Rama Medical College Hospital \& Research Centre, Kanpur.

FINANCIAL OR OTHER COMPETING INTERESTS: None

\section{NAME ADDRESS EMAIL ID OF THE} CORRESPONDING AUTHOR:

Dr. Probal Chatterji,

Flat M-301, Fortune City,

155, Old Jessore Road,

Kolkata-700132, India.

E-mail: probalch@hotmail.com

Date of Submission: 18/04/2015.

Date of Peer Review: 22/04/2015.

Date of Acceptance: 08/05/2015.

Date of Publishing: 16/05/2015. 